\begin{tabular}{|c|cc|c|}
\hline PORT SAID ENGINEERING RESEARCH JOURNAL & Faculty of Engineering - Port Said University \\
\hline & Volume 18 & No. $2 \quad$ September2014
\end{tabular}

\title{
Analytical Solution Developed For Predicting Transient Interface in Coastal Unconfined Aquifers
}

\author{
Mohamed M. A. Somaida ${ }^{1}$ (Faculty of Engineering, Port Said University)
}

\begin{abstract}
:
For predicting fresh-salt water interface in unconfined coastal aquifers, an equation has been developed to estimate the advance of interface which depends on; the densities of fresh and salt water, the hydraulic properties of the aquifer and the flow velocity components at the boundaries of the aquifer. The developed equation is tried in Sidi Kreir Locality, $32 \mathrm{~km}$ west of Alexandria (north-western coastal zone), constituting a coastal unconfined aquifer. The values for advance of interface estimated by the developed equation are compared with those computed using Ghyben-Herzberg relation and are found to have an order of magnitude agreement and are of nearer values. The developed equation is considered advantageous because it considers the hydraulic properties of the aquifer as well as the laws governing the potential flow of two liquids in the porous medium. Assessment of the goodness of the fitting of the compared values for advance of interface shows that; the analytical solution developed, seems to be successful procedure for predicting the movement of the fresh-salt water interface in coastal unconfined aquifers existing in favorable areas.
\end{abstract}

Keywords : Coastal unconfined aquifer-Water table- Predicting- Transient Interface- Velocity PotentialGoodness of Fitting

\section{Introduction}

In long-shore areas where permeable materials extend to considerable depth, salt water will underlie fresh water according to GhybenHerzberg relation, /1,2/, and will extend downward from the interface to the base of the impermeable material, Fig (1).

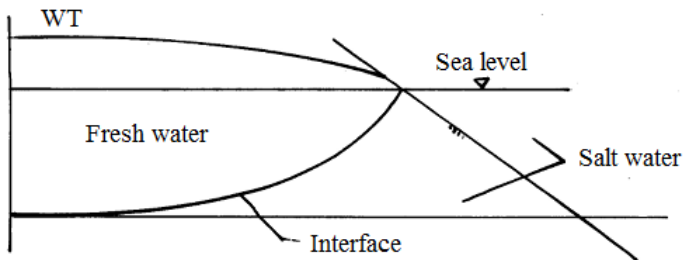

Figure 1: Definition sketch showing the freshsalt water interface in a coastal unconfined aquifer.

The fresh-water body assumes the form of a lens floating on the underlying sea water and is usually thickest at the central part of the land mass tapering to a thin edge at the shore margins, Fig (1). The flow moves from the thickest part of the lens outward to the shore line and other outlet margins. The magnitude of the fresh-water lens depends mainly on; land mass width, permeability, recharge and discharge and tidal range $/ 3 /$.

\section{Background}

In unconfined aquifers, when the water table drops, there will be a tendency for the fresh-salt water interface to rise. As water levels continue to decline, the interface will continue to advance until conditions of equilibrium are established.

Many studies have been made concerning with groundwater flow in coastal areas. Simple but practical one-dimensional steady-state analytical models, $/ 4,5 /$, have been developed based on the Ghyben-Herzberg relation and Dupuit's assumptions. Pinder and Cooper (1970),/6/, developed a numerical model for predicting movement of salt-water front in coastal areas. Two-dimensional solutions have been also developed by Van Deer Veer, /7/. More recently, for homogeneous and isotropic aquifers with straight boundaries, analytical solutions can be used to estimate the steady location for the sharp interface $18,9,10 /$. However the problem of unsteady (transient) interface for coastal unconfined aquifer will be studied beyond the scope here assuming flow velocity potentials in the porous medium and the natural hydrologic 
conditions existing in the area of study

\section{(1) Problem Formulation}

(1) Consider a two-dimensional potential flow through a selected control volume in a coastal unconfined aquifer, Fig(2), then the flow velocity potential $(\Phi)$ for fresh and salt-water region will be given respectively by :

$$
\Phi_{2}=-K_{s}\left(\frac{\partial p s}{w s}+z\right)
$$

Where $K_{f}$ and $K_{s}$ are the hydraulic conductivities of the fresh and salt-water regions respectively, $\mathrm{p}$ $=$ pressure at interface at coordinate $\mathrm{x}, w_{f}=$ specific weight of fresh water, $w_{s}=$ specific weight of salt water and $\mathrm{z}=$ elevation of interface above datum at coordinate $\mathrm{x}$

$$
\Phi_{1}=-K_{f}\left(\frac{p f}{w f}+z\right)
$$

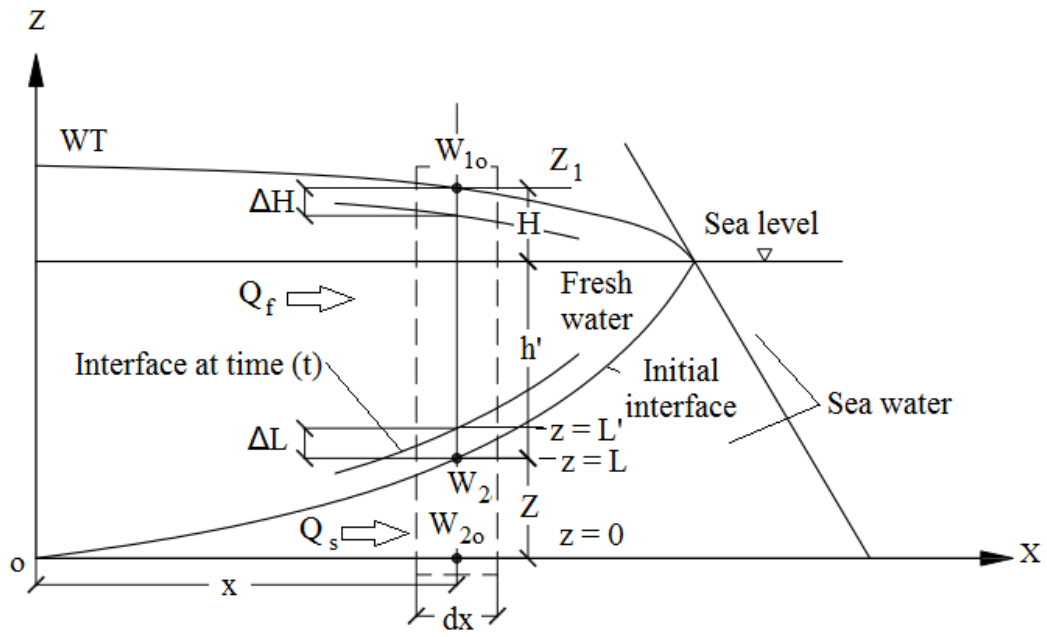

Figure 2: Details of flow through selected control volume in a coastal unconfined aquifer.

(2) Equality of pressure at interface in both liquids $\left(p_{f}=p_{s}\right)$ gives the following equation :

$$
\begin{gathered}
w_{f}=\left(\frac{\Phi 1}{K f}+z\right)=w s\left(\frac{\Phi 2}{K s}+z\right) \\
\text { Or } \mathrm{z}=\left(\frac{w f}{K f(w s-w f)}\right) \Phi 1-\left(\frac{w s}{K s(w s-w f)}\right) \Phi 2
\end{gathered}
$$

From which an approximate equation of interface is produced, $/ 11 /$ : $\mathrm{z}=A_{1} \Phi 1(\mathrm{x}, \mathrm{h}, \mathrm{t})-A_{2} \Phi 2(\mathrm{x}, \mathrm{h}, \mathrm{t})=\mathrm{L}$ func $(\mathrm{x}, \mathrm{t})(4)$ where $A_{1}=\frac{w f}{K f(w s-w f)} \quad, A_{2}=\frac{w s}{K s(w s-w f)}$ and $\mathrm{L}=$ level of interface above datum at coordinate $\mathrm{x}$. The total derivative for $\mathrm{L}$ in equation (4) will be : $\mathrm{dL}=\frac{\partial L}{\partial X} \mathrm{dx}+\frac{\partial L}{\partial t} \mathrm{dt}$

Divide by dt and multiply by porosity $\mathrm{n}$, : then :

$$
\begin{aligned}
& \mathrm{n}\left(\frac{d L}{d t}\right)=\left(\frac{\partial L}{\partial x}\right)\left(n \frac{d x}{d t}\right)=n \frac{\partial L}{\partial t}, \text { from which : } \\
& \mathrm{n}\left(\frac{\partial L}{\partial t}\right)+\left(\frac{\partial L}{\partial x}\right) u_{1}-w_{1}=0
\end{aligned}
$$

where $u_{1}$ and $w_{1}$ are the flow velocity components at interface for fresh-water region in the directions $\mathrm{x}$ and $\mathrm{z}$ respectively. By the same method, the following equation is reached for salt-water region :

$$
\mathrm{n}\left(\frac{\partial L}{\partial t}\right)=\left(\frac{\partial L}{\partial x}\right) u_{2}-w_{2}=0
$$

where $u_{2}$ and $w_{2}$ are the flow velocity components at interface for salt-water region in the directions $\mathrm{x}$ and $\mathrm{z}$ respectively.

(3) The general continuity equation for twodimensional flow applied on a control volume through the aquifer, Fig(2) is :

$\frac{\partial}{\partial x}(\rho u)+\frac{\partial}{\partial z}(\rho \mathrm{w})=-\left(\frac{\partial \rho}{\partial t}\right) n$

Equation(7) holds whether flow is steady or unsteady. For incompressible fluids, the density $\rho$ is constant and consequently, equation(7) simplifies to :

$$
\left(\frac{\partial u}{\partial x}\right)+\left(\frac{\partial w}{\partial z}\right)=0
$$

(4) For salt-water region, equation(8) will take the form :

$$
\begin{aligned}
& \left(\frac{d u 2}{d x}\right)+\left(\frac{d w 2}{d z}\right)=0, \text { integrating, then : } \\
& \int_{w 20}^{w 2} d w_{2}=-\left(\frac{d u 2}{d x}\right) \int_{0}^{L} d z \text { or } \\
& w_{2}-w_{2 o}=-\mathrm{L}\left(\frac{d u 2}{d x}\right)
\end{aligned}
$$

Using the velocity potential notation, $\left(\frac{d u 2}{d x}\right)=$ $\left(\frac{d 2 \Phi 2}{d \times 2}\right)=\Phi_{2 x x}$, then :

$w_{2}=-\mathrm{L} \Phi_{2 x x}+w_{2 o}$ 
where $w_{2 o}=$ vertical upward velocity of movement in salt-water region at $\mathrm{z}=0$. Similarly, for fresh-water region :

$$
\begin{gathered}
\left(\frac{d u 1}{d x}\right)+\left(\frac{d w 1}{d z}\right)=0 \\
\int_{w_{1}}^{w_{1 o}} d w_{1}=-\frac{d_{u 1}}{d x} \int_{L}^{z_{1}} d z \text { or } \\
w_{1}=-\left(z_{1}-\mathrm{L}\right) \Phi_{1 x x}+w_{10}
\end{gathered}
$$

Where $w_{10}=$ velocity of water moving downward vertically through the zone of aeration, resulting from the interaction between the porous medium and the liquid/11/and $z_{i f}=$ elevation of free surface from datum, $\mathrm{Fig}(2)$

(5) At free surface pressure $(p)=0$, then according to equation (1), $z_{1}=-\left(\frac{\phi 1}{K f}\right)$, accordingly equation (10) will take the form :

$$
w_{1}=\left(\frac{\phi 1}{K f}+\mathrm{L}\right) \Phi_{1 x x}+w_{1 o}
$$

Put $u_{1}=\Phi_{1 x}$ and $w_{1}$ expressed by equation(11) in equation(5) yields : $\mathrm{n}\left(\frac{\partial L}{\partial t}\right)+\left(\frac{\partial L}{\partial x}\right) \Phi_{1 x}+$ $\left(\frac{\Phi 1}{K f}+L\right) \Phi_{2 x x}-w_{1 o}=0$

Put $u_{2}=\Phi_{2 x}$ and $w_{2}$ expressed by equation (9) in equation(6) yields: $\mathrm{n}\left(\frac{\partial L}{\partial t}\right)+\left(\frac{\partial L}{\partial x}\right) \Phi_{2 x}+$ $L \Phi_{2 x x}-w_{2 o}=0$

(6) Combining equations (12) and (13) into a single equation by subtraction, then :

$$
\begin{aligned}
& 2 \mathrm{n}\left(\frac{\partial L}{\partial t}\right)+\left(\Phi_{1 x}+\Phi_{2 x}\right)\left(\frac{\partial L}{\partial x}\right)+\left(\frac{\Phi 1}{K f}+\right. \\
& 2 L) \Phi_{2 x x}-\left(w_{10}+w_{20}\right)=0
\end{aligned}
$$

To simplify the continuation of the present mathematical procedure, the term $\Phi_{2 x x}$ which is the second derivative of the velocity potential related to the salt-water region is usually of infinitesimal value in coastal unconfined aquifers ( 2.6x $10^{-5} \mathrm{Ks}$ ) in the present study. Hence, the term $\Phi_{2 x x}$ can be safely eliminated from equation(14) which will now take the following simpler form :

$$
2 \mathrm{n}\left(\frac{\partial L}{\partial t}\right)+\left(\Phi_{1 x}+\Phi_{2 x}\right)\left(\frac{\partial L}{\partial x}\right)-\left(w_{10}+\right.
$$

$\left.w_{20}\right)=0$

(6) From equation(4), $\mathrm{L}=A_{1} \Phi_{1}-A_{2} \Phi_{2}$, differentiate with respect to $\mathrm{x}$ :

$\left(\frac{\partial L}{\partial x}\right)=A_{1} \Phi_{1 x}-A_{2} \Phi_{2 x}$, Substitute in (15), then :

$2 \mathrm{n}\left(\frac{\partial L}{\partial t}\right)+\left(\Phi_{1 x}+\Phi_{2 x}\right)\left(A_{1} \Phi_{1 x}-A_{2} \Phi_{2 x}\right)=$

$\left(w_{10}+w_{20}\right) \quad(16)$

Expansion of brackets and simplifying equation(16) yields :

$$
\begin{aligned}
& 2 \mathrm{n}\left(\frac{\partial L}{\partial t}\right)+A_{1}\left(\Phi_{1 x}\right)^{2}+A_{2}\left(\Phi_{2 x}\right)^{2}+ \\
& \left(A_{1}-A_{2}\right) \Phi_{1 x} \Phi_{2 x}=\left(w_{10}+w_{20}\right)
\end{aligned}
$$

(7) From equation(3), $\left(\frac{\Phi 1}{w s K f}\right)=\left(\frac{\Phi 2}{w f K s}\right)+$ $\left(\frac{z}{w f}\right)-\left(\frac{z}{w s}\right)$, this equation can be safely approximated since, $w_{f}$ and $w_{s}$ (densities) of fresh and sea water are of nearer values :

$\Phi_{2}=\frac{w_{f}}{w_{s}} \Phi_{1}$ or $\Phi_{2}=A_{3} \Phi_{1}$, However equation(17) will be :

$$
\begin{aligned}
& 2 \mathrm{n}\left(\frac{\partial L}{\partial t}\right)+\left(A_{1}+A_{2}\left(A_{3}\right)^{2}+A_{1} A_{3}-A_{2} A_{3}\right) \\
& \left(\Phi_{1 x}\right)^{2}=\left(w_{10}+w_{20}\right) \text { or } \\
& 2 \mathrm{n}\left(\frac{\partial L}{\partial t}\right)+A\left(\Phi_{1 x}\right)^{2}=\left(w_{10}+w_{20}\right)
\end{aligned}
$$

Where the parameter $\mathrm{A}$ is a constant $=\left(A_{1}+A_{2}\right.$ $\left.\left(A_{3}\right)^{2}+A_{1} A_{3}-A_{2} A_{3}\right)$

In equation $(19)$, put $\left(u_{1}\right)^{2}=\left(\Phi_{1 x}\right)^{2}$, where $u_{1}=$ horizontal velocity of flow in the fresh-water region, then :

$$
\left(\frac{\partial L}{\partial t}\right)=\left(\frac{(w 20+w 10)-A u 1^{2}}{2 n}\right)
$$

In equation (21), using the total derivative instead of partial derivative and integrating between the limits, at $\mathrm{t}=0, \mathrm{z}=\mathrm{L}$ and at $\mathrm{t}=\mathrm{t}, \mathrm{z}$ $=\mathrm{L}$ ', Fig (2), then:

$$
\int_{L}^{L^{\prime}} d L=\left(\frac{(w 20+w 10)-A u 1^{2}}{2 n}\right) \int_{0}^{t} d t \quad \text { or }
$$

$\left.\Delta L=\frac{(w 20+w 10)-A u 1^{2}}{2 n}\right) t$

Where $\Delta \mathrm{L}=$ the length of advance of interface in a time $t$. If the specific gravity of sea water is proposed 1.025 and that of fresh water $=1.0$ and assuming that the fresh and salt-water regions have equal hydraulic conductivities $\left(K_{f}=K_{s}=\right.$ $\mathrm{K})$, then the first and fourth terms of the parameter A of equation(20) are equal and eliminates each other, while the second and third terms in the same parameter A, have the same magnitude $\left(\frac{39}{K}\right)$, and can be added such that equation (22) will take the final form :

$$
\Delta \mathrm{L}=\left(\frac{K(w 20+w 10)-78 u 1^{2}}{2 n K}\right) t
$$

where $\mathrm{K}$ = hydraulic conductivity of the aquifer. Equation (23) can be employed to estimate the seasonal rise of interface $(\Delta \mathrm{L})$ in a coastal unconfined aquifer. Derivation of equation (23) is based on the following assumptions :

(1) The aquifer is homogeneous and isotropic and unconfined.

(2) Two-dimensional potential flow in porous medium.

(3) The interface between salt and fresh-water is quiet sharp and the transition zone is ignored. 
(4) The initial interface is taken at the time where the water table attains its maximum levels and is determined according to Ghyben-Herzberg relation.

(5)The rate of change of the slope of interface is very little and negligible.

(6) The rise of interface is caused by the subsurface outflow of fresh groundwater to the underlying salt base

(7) The fresh and salt-water regions have equal hydraulic conductivity coefficients.

(8) The specific gravity of sea water is proposed 1.025 and that of fresh water is 1.0

(9) The tidal effects are ignored.

\section{Application Example}

The equation developed for estimating the seasonal advance of interface is applied on the coastal unconfined aquifer in Sidi Kreir Locality, $32 \mathrm{~km}$ west of Alexandria, the north western coastal zone, Egypt, Fig(3), /12/.

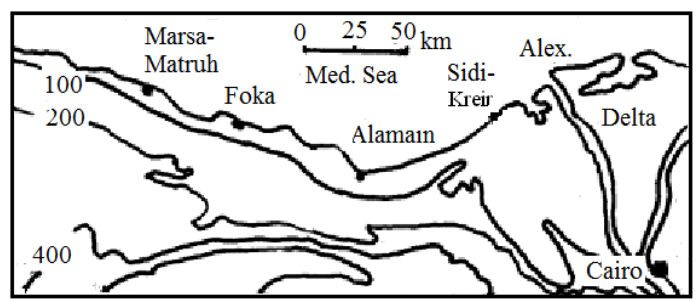

Figure 3: Index map showing the location of Sidi-Kreir locality north western coastal zone, Egypt.

The aquifer consists of permeable carbonate rocks of Pleistocene age, . The aquifer is recharged from rainfall, a large part of it percolates downward to form a fresh groundwater-lens floating on top of the underlying sea water according to GhybenHerzberg relation, Fig (4).

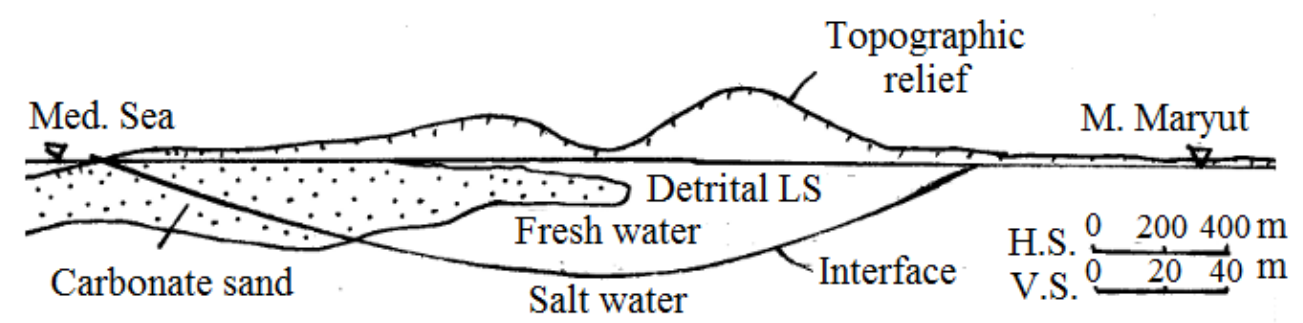

Figure 4: Cross section showing the fresh water lens floating on top of sea water in Sidi-Kreir locality,/12/

The thickness of the aquifer depends on the amount of recharge to the aquifer and the level of water table above sea level. The studied aquifer has an average porosity of 0.385 from coreanalysis and an average hydraulic conductivity of $9.4 \mathrm{~m} /$ day from pumping tests, $/ 12,13 /$.

The present aquifer discharges mainly in the Mediterranean sea and Mallahet Maryut. The general direction of groundwater movement is northeast ward north the groundwater divide and southwest ward south the groundwater divide, Figs $(5,6)$.

According to $/ 12 /$, the long-term studies of water-table fluctuations in Sidi Kreir, shows that, the water levels attain the highest values in February, Fig(5) and the lowest levels in November, Fig(6). These levels are accepted as present-day representative levels. However, the seasonal period of decline of water table is considered 9 months (270 day).

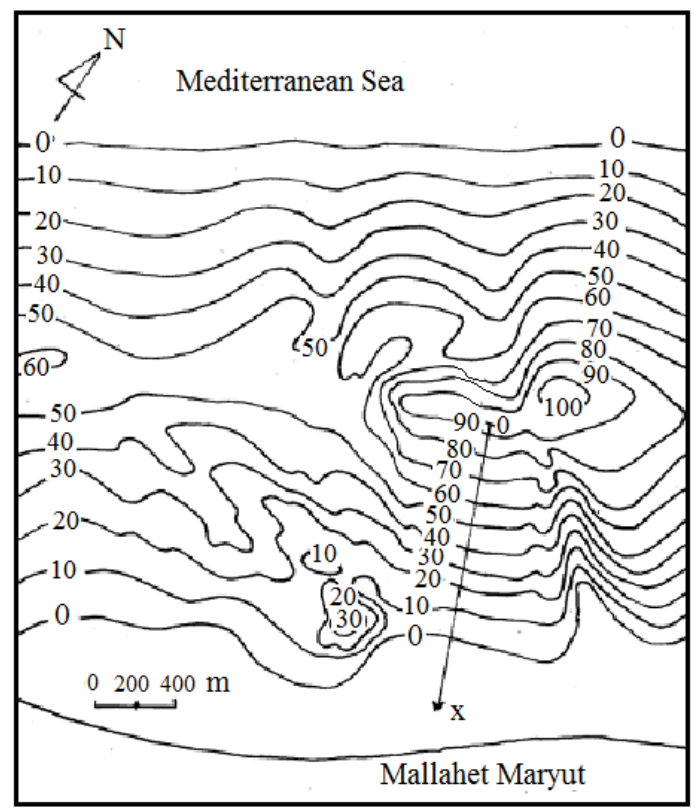

Figure 5: Highest level water-table contour map at Sidi-Kreir locality (February), /12/ 


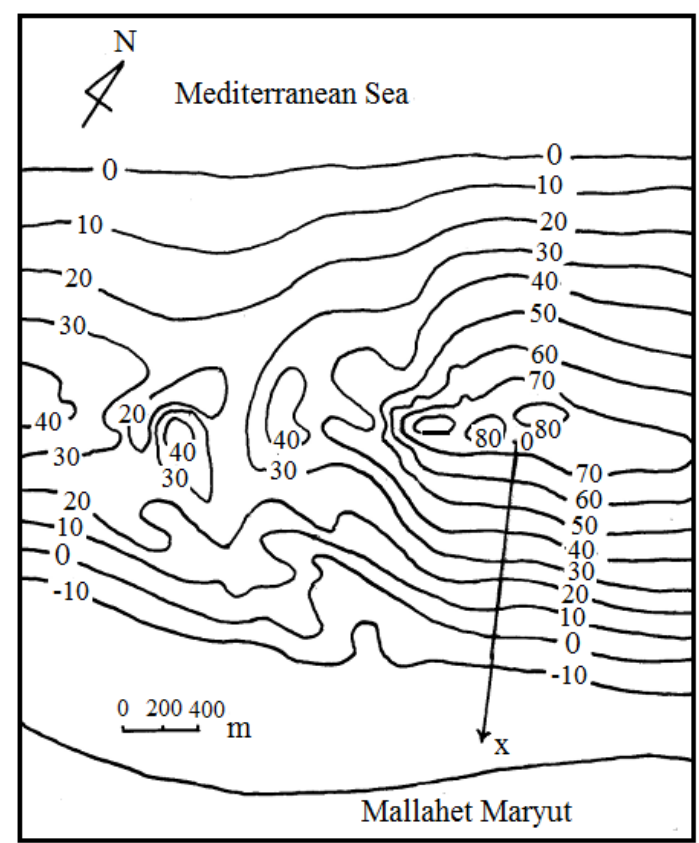

Figure 5: Lowest level water-table contour map at Sidi-Kreir locality (November), /12/
Application of the developed equation on the studied aquifer is made in the following steps :

(1)The initial interface at $t=0$, is determined by the use of the water -table contour map of Fig(5) and Ghyben-Herzberg principle

(2) Datum to which the depth of water table or interface are referred is the horizontal plane touching the apex of the interface. In depth it is about $40 \mathrm{~m}$ below sea level, /12/

(3) The $x$-direction is represented by a profile extending down gradient from the center of the lens to the south parallel to the direction of groundwater movement to Mallahet Maryut, Figs $(5,6)$. Calculations are tried on selected points with $\mathrm{x}$ coordinates from the origin as given in Table(1)

(4) The horizontal velocity component $u_{1}$, is estimated using the slope of water table in Fig(5) at every selected point and multiplying it by the hydraulic conductivity of the aquifer $(9.4 \mathrm{~m} /$ day $)$. The results of $u_{1}$ are given in Table (1)

\section{Calculations and Results}

Table 1: Computed hydrologic parameters necessary for application of the developed equation on the studied aquifer in Sidi Kreir Locality

\begin{tabular}{|c|c|c|c|c|c|c|c|c|}
\hline $\mathbf{x}(\mathbf{m})$ & $\begin{array}{c}\text { Initial elev. } \\
\text { of WT }(\mathbf{m})\end{array}$ & $\begin{array}{c}\text { Thickness of } \\
\text { aquifer }(\mathbf{m})\end{array}$ & $\mathbf{S}(\mathbf{H G})$ & $\begin{array}{c}\mathbf{u}_{\mathbf{1}} \\
(\mathbf{m} / \mathbf{d a y})\end{array}$ & $\begin{array}{c}\text { Final elev. } \\
\text { Of WT }(\mathbf{m})\end{array}$ & $\begin{array}{c}\text { Drop } \\
\text { of WT, } \\
\mathbf{\Delta H}(\boldsymbol{m})\end{array}$ & $\begin{array}{c}\mathbf{W}_{\mathbf{2 0}} \\
(\mathbf{m} / \mathbf{d a y})\end{array}$ & $\begin{array}{c}\mathbf{W}_{\mathbf{1 0}} \\
(\mathbf{m} / \mathbf{d a y})\end{array}$ \\
\hline 0.0 & 1.025 & 42 & 0.000938 & 0.008817 & 0.8 & 0.225 & 0.03333 & 0.03318 \\
\hline 53.3 & 0.9 & 36.9 & 0.000938 & 0.008817 & 0.7 & 0.2 & 0.02963 & 0.02942 \\
\hline 160 & 0.79 & 32.8 & 0.000833 & 0.00783 & 0.6 & 0.19 & 0.02852 & 0.02830 \\
\hline 293.3 & 0.7 & 28.7 & 0.000752 & 0.00707 & 0.53 & 0.17 & 0.02519 & 0.02498 \\
\hline 426.7 & 0.6 & 24.6 & 0.000833 & 0.007833 & 0.43 & 0.165 & 0.02444 & 0.02429 \\
\hline 533.3 & 0.5 & 20.5 & 0.000938 & 0.008817 & 0.34 & 0.16 & 0.0237 & 0.02349 \\
\hline 640 & 0.4 & 16.4 & 0.000937 & 0.008808 & 0.25 & 0.15 & 0.02222 & 0.02053 \\
\hline 746.7 & 0.3 & 12.3 & 0.000938 & 0.008817 & 0.16 & 0.14 & 0.02074 & 0.02201 \\
\hline 853.3 & 0.2 & 8.2 & 0.000081 & 0.00861 & 0.1 & 0.10 & 0.01481 & 0.0146 \\
\hline 965 & 0.087 & 4.1 & 0.00075 & 0.00705 & 0.0 & 0.087 & 0.0129 & 0.01269 \\
\hline 1120 & 0.0 & 0.0 & 0.000645 & 0.006063 & -0.02 & 0.02 & 0.00396 & 0.00275 \\
\hline
\end{tabular}

(5) The vertical upward velocity of salt-water front $w_{20}$ at $\mathrm{z}=0$, at every selected point, is evaluated according to the boundary condition; at $\mathrm{x} \geq 0, \mathrm{z}=0, w_{20}=w_{2}$. Knowing the water-table level drops through 9 months $(\Delta \mathrm{H})$ at the selected points, Table(1), then $w_{20}$ is computed using Ghyben-Herzberg relation where the results are shown in Table (1).

(6) For evaluation of the vertical downward velocity in the aeration zone $w_{10}$, use is made of the two flow nets constructed for the studied aquifer, one before the rain season (November) and the other after the global rainfall in (February), /14/, where quantitative analysis of the flow nets shows that, the amount of recharge added to the aquifer is $25.4 \mathrm{~mm}, / 14 /$. This means that, the substantial recharge begins with the rain in November and by February, the water table attains its maximum level. The strata between the land surface and water table have drained $25.4 \mathrm{~mm}$ of recharge to move downward 
and reach the zone of saturation in 4 months. Hence, the possible average rate of downward travel of groundwater in the zone of aeration may be $(25.4 / 4=6.35 \mathrm{~mm}$ per month $)$ or $w_{10}$ averages $(0.000212 \mathrm{~m} /$ day $)$. This is an acceptable rate, because it is evaluated according to the actual records and the natural hydrologic conditions of the study area. It must be noted that this velocity will have a negative value because it is oriented in the negative direction of $\mathrm{z}$.
(7) Finally, all the estimated parameters given in Table(1), are used to apply the developed analytical solution to determine the seasonal advance of interface $(\Delta L)$ after 9 months as illustrated in Table(2). For comparison purposes, Table(2) includes also, the corresponding values of $(\Delta \mathrm{L})$ estimated using Ghyben-Herzberg relation.

Table 2: Results of advance of interface $(\Delta L)$ using the Analytical solution (AS) and Ghyben-Herzberg relation $(\mathrm{GHR})$ for the studied aquifer

\begin{tabular}{|c|c|c||c|c|c|}
\hline $\begin{array}{c}\text { Coordinate } \mathrm{x} \\
(\mathrm{m})\end{array}$ & $\begin{array}{c}\Delta \mathrm{L}(\mathrm{AS}) \\
(\mathrm{m})\end{array}$ & $\begin{array}{c}\Delta \mathrm{L}(\mathrm{GHR}) \\
(\mathrm{m})\end{array}$ & $\begin{array}{c}\text { Coordinate } \mathrm{x} \\
(\mathrm{m})\end{array}$ & $\begin{array}{c}\Delta \mathrm{L}(\mathrm{AS}) \\
(\mathrm{m})\end{array}$ & $\begin{array}{c}\Delta \mathrm{L}(\mathrm{GHR}) \\
(\mathrm{m})\end{array}$ \\
\hline 0.0 & 11.4 & 9 & 640 & 7.5 & 6 \\
\hline 53.3 & 10.1 & 8 & 746.7 & 7 & 5.6 \\
\hline 160 & 9.76 & 7.7 & 853.3 & 4.9 & 4 \\
\hline 293.3 & 8.62 & 6.8 & 965 & 4.3 & 3.48 \\
\hline 426.7 & 8.35 & 6.6 & 1120 & 0.86 & 0.8 \\
\hline 533.3 & 8.02 & 6.4 & \multicolumn{3}{|c}{} \\
\hline
\end{tabular}

\section{Analysis of The Results and Conclusions}

Correlation of the results of seasonal advance of interface $(\Delta \mathrm{L})$ in the studied aquifer given in
Table (2) and their plot in Fig (7), indicates the following :

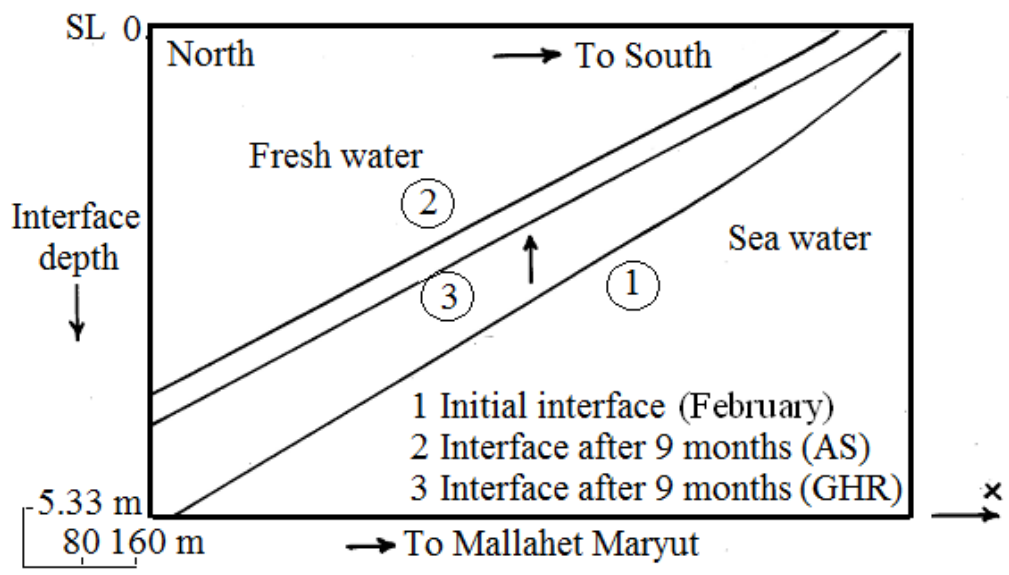

Figure 7: Plot of initial interface (February) in Sidi-Kreir locality and the corresponding plots after 9 months using analytical solution (AS) and Ghyben-Herzberg relation (GHR).

(1)The values of $\Delta \mathrm{L}$ computed by the developed analytical solution (AS) and those by Ghyben-Herzberg relation (GHR) are found to have an order of magnitude agreement . It is not necessary that the compared values must be exactly equal, because the analytical solution is developed for a potential flow through a porous medium, while the Ghyben-Herzberg relation indicates successive periodical static conditions
(2) The values of $\Delta \mathrm{L}$ calculated by the analytical solution , are larger than those estimated by the Ghyben-Herzberg relation. The difference in magnitude ranges from 0.06 to $2.4 \mathrm{~m}$, (concluded from Table(2), being maximum at the groundwater divide and smaller at the shore line of Mallahet Maryut. This is attributed to the gradual reduction in the thickness of the fresh-water aquifer down gradient towards the Mallaha by subsurface 
outflow of fresh-groundwater to the underlying salt base. On the average, the difference in $\Delta \mathrm{L}$ is $1.23 \mathrm{~m}$, which resembles to an average drop of the water table of 3.075 $\mathrm{cm}$ in 9 months or about $0.114 \mathrm{~mm} /$ day.

(3) The agreement of the developed analytical solution is considered satisfactory, because the solution considers the natural hydrological conditions of the area as well as the laws governing the potential flow of two liquids in porous medium, these are being out of consideration in the Ghyben-Herzberg principle.

(4) Assessment of the goodness of the fitting of $\Delta \mathrm{L}$ in both solutions, shows that, the square correlation coefficient (R2) is 0.999 and the root mean square error ( RMSE) is $2.03, / 15 /$. This indicates a strong relation exists between the compared $\Delta \mathrm{L}$ values, $\operatorname{Fig}(8)$.

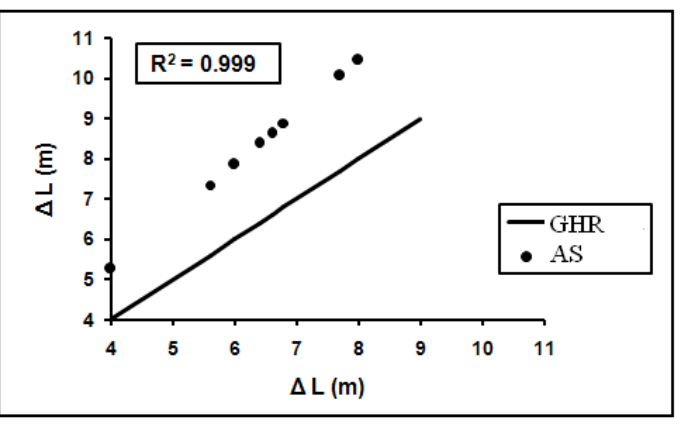

Figure 8: correlation analysis for advance of interface results in Sidi Kreir Locality

(5) Finally, it may be concluded that, the developed analytical solution is a successful procedure for predicting the seasonal advance of interface in coastal unconfined aquifers being found in favorable areas

\section{Nomenclature}

$\Phi_{1}=$ Velocity potential for fresh-water region

$\Phi_{2}=$ Velocity potential for salt-water region

$K_{f}=$ Hydraulic conductivity of fresh-water region

$K_{S}=$ hydraulic conductivity of salt-water region

$\mathrm{K}=$ average hydraulic conductivity of the aquifer

$\mathrm{P}=$ pressure along interface at any coordinate $\mathrm{x}$

$w_{f}=$ specific weight of fresh water

$w_{s}=$ specific weight of salt water

$\mathrm{z}=$ elevation of interface above datum at coordinate $\mathrm{x}$

$A_{1}, A_{2}, A_{3}=$ constant coefficients

$\mathrm{L}=$ level of interface at coordinate $\mathrm{x}$

$\mathrm{n}=$ average porosity of the aquifer

$u_{1}, w_{1}=$ flow velocity components in the fresh-water region of the aquifer in the $\mathrm{x}$ and $\mathrm{z}$ directions respectively

$u_{2}, w_{2}=$ flow velocity components in the salt-water region of the aquifer in the $\mathrm{x}$ and $\mathrm{z}$ directions respectively $w_{20}=$ vertical upward velocity of advance of salt water at $\mathrm{z}=0$ at any selected point

$w_{10}=$ velocity of water movement vertically downward in the aeration zone
$\Phi_{1 x}=$ rate of change of fresh-water velocity potential with horizontal distance $\mathrm{x}$

$\Phi_{1 x x}=$ second derivative of fresh-water velocity potential

$\Phi_{2 x}=$ rate of change of salt-water velocity potential with horizontal distance $\mathrm{x}$

$\Phi_{2 x x}$ second derivative of salt-water velocity potential

$\Delta \mathrm{H}=$ seasonal drop of water table

$\Delta \mathrm{L}=$ seasonal advance of fresh-salt water interface

$\mathrm{t}=$ seasonal period of advance

$\mathrm{S}$ = slope of water table ( hydraulic gradient )

$\mathrm{W} \mathrm{T}=$ water table

\section{References}

/1/ Badon Ghyben,W., 1889 : Notes on the probable results of the proposed well drilling near Amestrdam, Tydschrift,Van het Koninkyhy Institute Van Ingenieur. The Hague, The Nether Lands, 21pp.

12/ (Herzberg, A., 1901 : The water supply on parts of the north sea coast, Journal Gasbeleucht. U. Jahrg 44, Munich,Germany

/3/ Urish, D.W., 1980 : Asymmetric variation of Ghyben-Herzberg lens, ASCE, Vol. 106, N0. Hy7, 11491158 (4)Fetter, C.W., 1972 : Saline water interface beneath oceanic islands.

/4/ Fetter, C.W., 1972 : Saline water interface beneath oceanic islands. Water Resources Research Vol. 8, No. 5, 1307-1315

/5/ Henry, H.R., 1964 : Interfaces between salt water and fresh water in coastal aquifers. U.S. Geological Survey Water Supply Paper 1613-C, 35-69

/6/ Pinder, G.F., and Cooper, H.H., 1970 : A numerical technique foe calculating the transient position of the salt water front. Water Resources, Res. 6, 875-882

17/ Van Der Veer, P., 1977 : Analytical solution for steady interface flow in a coastal aquifer involving a phreatic surface with precipitation. Journal of Hydrology, Vol.34, 1-11

/8/ Bear, J., 1979 : Hydraulics of groundwater. McGrawHill Inc, 567pp

19/ Cheng, A.H., Halhol, D., and Quazar, D., 200 : Pumping optimization in the salt-water intruded coastal aquifers. Water Resources, Res., Vol. 36, No.8, 21552165

/10/ Abdel Gawad, H.A., et al, 2004 : Optimal utilization of unconfined coastal aquifers. MEJ(Mansoura Eng. Journal), Faculty of Eng., C20-C32

/11/ Kochina, Pa., Ya., 1962 : Theory of groundwater movement. Princeton University Press ., New Jersy, 542543

/12)/ Somaida, M.M., 1978 : A study of the fresh-water aquifer in Sidi Kreir area, west of Alexandria. A Ph.D., Thesis, Faculty of Eng., Cairo University.

/13/ Somaida, M.M., 1985 : A study of the problem of partial penetration of the pumped wells and anisotropy in unconfined aquifers. SB( scientific Bulletin of AinShams University), Faculty of Eng., Vol. 18 
/14/ Somaida, M.M., 1984 : Flow nets analysis of fresh groundwater at SIDI Kreir, Mediterranean sea western coastal zone. Journal of the Geological Society of Egypt(Accepted Paper)

/15/ Agresti, A., 1996 : An Introduction to categorical data analysis. Jhon-Wiley Inc, New York

\section{Author's Information}

1 Professor of Hydraulics in the Department of Civil Eng. , Faculty of Eng., Port-Said University. The Author is very interesting in the fields of, Groundwater Hydrology, Hydraulic Engineering and Applied fluid Mechanics. The author has many publications in these fields (38 papers) 